\title{
Website Penjualan Pigura dengan Fitur Frame Customization
}

\author{
Steven Christian Purnomo, Departemen Informatika, Institut Sains dan Teknologi Terpadu Surabaya, \\ Suhatati Tjandra, Departemen Informatika, Institut Sains dan Teknologi Terpadu Surabaya, dan \\ Amelia Alexandra, Departemen Informatika, Institut Sains dan Teknologi Terpadu Surabaya
}

\begin{abstract}
Abstrak-Semakin berkembangnya dunia pigura di Indonesia saat ini, semakin banyak produk pigura baru yang muncul serta lebih menarik. Namun dengan semakin berkembangnya dunia pigura dan teknologi saat ini, tidak diimbangi dengan menjual produk pigura ini ke masyarakat luas secara online. Banyak masyarakat saat ini yang ingin membeli pigura harus datang terlebih dahulu ke toko secara offline dan calon pembeli hanya ditawarkan dengan produk pigura yang stoknya ada saja. Padahal pigura sangat banyak macamnya dan selalu digunakan oleh masyarakat untuk memasang foto kenangan, seperti kelulusan atau foto kenangan pernikahan di rumah.

Untuk menyelesaikan masalah tersebut, maka dibuatlah sebuah website penjualan pigura. Website ini akan dibuat menjadi dua bagian, yaitu website untuk admin perusahaan pigura dan website untuk customer. Website admin digunakan untuk memproses data master, pembayaran, input nomor resi, dan report sedangkan website customer digunakan untuk melakukan proses pemesanan pigura dan customization frame.

Dengan dibuatnya website ini diharapkan perusahaan pigura dapat menghemat biaya operasional dan memudahkan perusahaan pigura untuk mengenalkan, serta memasarkan produknya secara mudah. Website yang dibuat juga dapat membantu customer untuk melihat model frame dengan model yang terbaru, serta melakukan customization frame yang diinginkan dengan mudah.
\end{abstract}

Kata Kunci-Customization Frame, Frame, Pemesanan, Pigura, Website Pigura

\section{Pendahuluan}

$\mathrm{B}$ ingkai foto (photo frame) atau bingkai gambar (picture frame) atau biasanya sering disebut dengan pigura adalah tepi dekoratif yang dibuat untuk memasang, melindungi, dan memajang sebuah gambar, foto, atau lukisan. Bentuk bingkai biasanya berbentuk persegi panjang yang terbuat dari kayu dan biasanya dilapisi oleh kaca untuk melindungi bagian lukisan atau gambar yang dipasang. Biasanya ukuran pigura yang sering digunakan adalah pigura dengan ukuran foto $3 \mathrm{R}, 4 \mathrm{R}, 6 \mathrm{R}, 10 \mathrm{R}, 10 \mathrm{RS}$, dan 12R.

Steven Christian Purnomo, Departemen Teknik Informatika, Sekolah Tinggi Teknik Surabaya, Surabaya, Jawa Timur, Indonesia (e-mail: christiansteven67@gmail.com)

Suhatati Tjandra, Departemen Teknik Informatika, Sekolah Tinggi Teknik Surabaya, Surabaya, Jawa Timur, Indonesia (e-mail: tati@stts.edu)

Amelia Alexandra, Departemen Teknik Informatika, Sekolah Tinggi Teknik Surabaya, Surabaya, Jawa Timur, Indonesia (e-mail: sandra@stts.edu)
Seiring berkembangnya jaman, pigura saat ini dibuat menggunakan dari kumpulan serbuk kayu (polyframe) karena sifatnya yang ringan tetapi tetap kuat. Terdapat pigura yang menggunakan linen maupun tidak. Hal tersebut dikarenakan selain memperindah pigura juga digunakan untuk memperkokoh pigura agar semakin kuat dan tidak mudah pecah pada bagian ujung sisi pigura.

Marcello Migliore [1] mengintegrasikan gambar digital (foto atau video) kedalam sebuah frame. Menurut penelitiannya, orang yang melihat gambar tersebut pada sebuah frame menjadi lebih tertarik dan orang tersebut menjadi lebih rileks karena adanya frame tersebut yang menghiasi. Untuk membantu pengguna untuk memilih model pigura yang diinginkan dengan mudah dan rileks serta tidak diburu oleh waktu sehingga timbul ide untuk mengembangkan website tersebut.

Berdasarkan aplikasi website yang dikembangkan yaitu agar user dapat melihat model pigura dan supaya user dapat melakukan kustomisasi frame. Penjelasan yang diberikan tentang library serta API ini dapat membantu pembaca lebih mengerti mengenai sistem ini secara garis besar.

Komponen-komponen yang akan dijelaskan adalah komponen yang digunakan untuk membuat aplikasi website tersebut, diantaranya adalah Codeigniter, RajaOngkir, MyLiveChat, Konva JS, Cron Jobs, dan Google API Client yang digunakan untuk membantu pembuatan website ini. Proses penjelasan akan dilakukan secara ringkas dan padat mengenai tiap-tiap komponen. Berikut ini merupakan penjelasan terhadap tiap-tiap komponen tersebut.

\section{TINJAUAN PUSTAKA}

\section{A. Framework Codeigniter (CI)}

Menurut Rahmadiansyah \& Irawan [2], CodeIgniter (CI) merupakan sebuah framework pemrograman web dengan menggunakan bahasa PHP. Framework ini ditulis dengan menggunakan bahasa php versi 4 dan versi 5 oleh Rick Ellislab yang menjadi CEO Ellislab, Inc. dan dipublikasikan dengan lisensi di bawah Apache/BSD Open Source. Di dalam CI terdapat beberapa macam kelas yang berbentuk library dan helper yang berfungsi untuk membantu pemrogram dalam mengembangkan aplikasinya. Berikut merupakan cara kerja framework CI [3]. Konsep pada framework CodeIgniter yaitu MVC (Model View Controller). MVC adalah sebuah pola rancangan yang 
memungkinkan para pengembang memisahkan kode program kedalam tiga kelompok, yaitu model, view dan controller [3]. Model, bagian ini berisi kode yang digunakan untuk koneksi dan mengakses database. View, berisi kodekode HTML dan PHP yang digunakan untuk menampilkan informasi ke layar browser. Biasanya kode-kode yang berhubungan dengan format tampilan, misalnya huruf, form, warna dan lain-lain. Controller, berisi kode-kode script yang menjalankan fungsi aturan bisnis aplikasi dan menjadi perantara antara Model dan View serta seluruh sumber daya yang dibutuhkan untuk memproses permintaan layanan HTTP untuk ditampilkan dalam halaman web [2].

\section{B. Framework Konva}

Menurut website resmi pada halaman documentation dari Konva, Konva adalah sebuah framework HTML5 Canvas JavaScript yang memperluas konteks 2D dengan mengaktifkan interaktivitas kanvas untuk aplikasi desktop dan mobile. Konva memungkinkan animasi berkinerja tinggi, transisi, nesting simpul, layering, penyaringan, caching, penanganan event untuk aplikasi desktop dan mobile, dan masih banyak lagi. Library ini yang digunakan untuk mengembangkan sistem kustomisasi sehingga gambar frame yang terlihat pada website dapat tampil dengan sesuai yang diinginkan.

\section{Framework Bootsrap}

Framework Bootstrap Menurut Zakir [4], Bootstrap merupakan sebuah framework yang dapat menyelesaikan permasalahan dalam mendesain web. Slogan dari framework ini adalah "sleek, intuitive, and powerful front-end framework for faster and easier web development", yang berarti user dapat mendesain sebuah website dengan lebih rapi, cepat dan mudah. Selain itu Bootstrap juga responsive terhadap banyak platform, artinya tampilan halaman website yang menggunakan Bootstrap ini akan tampak tetap rapi, baik versi mobile maupun desktop.

\section{MySQL}

Menurut Supono \& Putratama [5], MySQL adalah sistem manajemen database SQL yang bersifat Open Source dan paling populer saat ini. Sistem Database MySQL mendukung beberapa fitur seperti multithreaded, multi-user, dan SQL database management system (DBMS). Database ini dibuat untuk keperluan sistem database yang cepat, andal dan mudah digunakan.

\section{TAHAPAN PENELITIAN}

Berikut ini adalah langkah-langkah pengerjaan sistem ini.

1) Mengumpulkan semua kebutuhan dan informasiinformasi yang dibutuhkan dalam pembangunan software.

2) Mengumpulkan informasi harga bahan beserta gambar frame yang diperlukan.

3) Membuat sketsa desain website dan diagram database. Sketsa desain website dibuat dari gambaran kasar yang digambar di kertas.

4) Mendesain website menggunakan front-end framework diikuti dengan animasi-animasinya.

5) Membuat database dengan DBMS MySQL, trigger, dan function-function yang diperlukan.
6) Memulai pengembangan software. Setiap fungsi yang telah dibuat akan diuji coba apakah sudah benar atau belum.

7) Testing akhir dan revisi bila ada yang perlu diperbaiki atau terdapat bug.

8) Melakukan hosting website yang telah dibuat agar dapat diakses oleh masyarakat.

\section{ANALISA DAN DESAIN SISTEM}

Berikut akan dijelaskan lebih detail mengenai langkahlangkah proses kustomisasi frame yang dibuat beserta dengan perhitungan harga dan berat yang secara otomatis berubah dan tampil sesuai dengan yang dipilih oleh. Penjelasan akan dibagi menjadi subbab-subbab terpisah. Pada awal melakukan kustomisasi frame, user diharuskan untuk memilih model frame yang diinginkan.

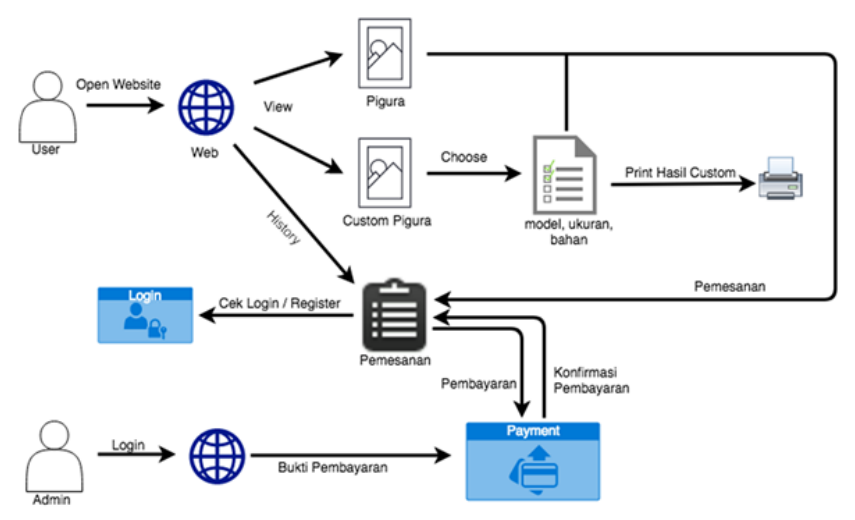

Gambar. 1. Alur Sistem

User memilih katalog pigura jadi dan menentukan jumlah pigura yang ingin dibeli. Bila user ingin melakukan customization, maka user dapat melihat model frame pigura dan memilih model frame pigura mana yang ingin digunakan oleh user untuk di custom. Pengguna bisa memilih model frame mana yang diinginkan oleh user untuk dipesan. Model frame yang dapat dipilih adalah model frame minimalis, model frame ukir atau klasik, dan model frame linen.

Setelah user memilih, akan muncul pop up untuk memilih apakah user ingin lanjut mengedit pigura yang ingin di custom atau melakukan upload foto agar foto yang diupload oleh user akan tampil saat user melakukan customization. Setelah itu user akan diarahkan ke halaman selanjutnya dan user diminta untuk menentukan ukuran panjang dan lebar pigura yang diinginkan, tebal pinggiran frame, menggunakan linen atau tidak, kaca, dan cover atau penutup. Setelah tombol finish ditekan maka akan pigura yang telah di custom akan masuk ke dalam cart. Kemudian dilakukan pengecekan apabila user belum melakukan login, maka user akan diarahkan kehalaman login. Apabila user belum memiliki akun maka user dapat register terlebih dahulu. Bila register dirasa terlalu rumit, maka user bisa login langsung menggunakan google account. Setelah itu, pembeli diharuskan untuk melakukan pembayaran melalui ATM dan mengupload bukti transfer tersebut. 


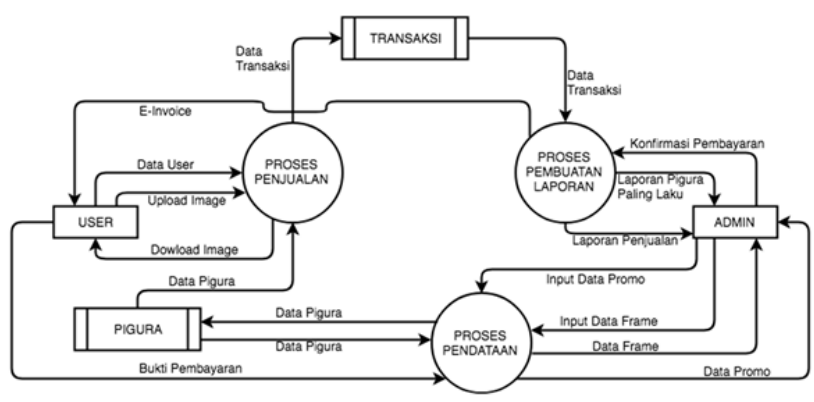

Gambar. 2. DFD Sistem Penjualan Frame

Seperti yang digambarkan pada DFD (gambar 2), user memilih pigura dan masuk ke dalam proses penjualan. Proses penjualan tersebut dilanjutkan dengan menyimpan data transaksi tersebut. Transaksi tersebut kemudian diproses menuju pembuatan laporan sehingga user dapat melihat E-invoice dan admin dapat melihat laporan-laporan yang ada. Admin juga dapat menambahkan data baru dan melihat seluruh data pada master data. Proses tersebut kemudian dilanjutkan dengan memproses data tersebut. Data tersebut kemudian akan disimpan ke dalam pigura. Data pigura tersebut kemudian yang akan tampil sehingga dapat dilihat dan dipilih oleh user.

\section{A. Upload Image}

Proses upload image merupakan awal untuk melakukan kustomisasi setelah user memilih model frame yang diinginkan. Image yang diupoad oleh user merupakan image yang nantinya akan tampil pada proses kustomisasi sehingga user dapat melihat apakah image tersebut tampak sesuai dengan frame yang dipilih sebelumnya.

\section{B. Perhitungan Ratio Gambar}

Pada subbab sebelumnya adalah proses upload image yang di upload oleh user. Proses tersebut kemudian akan mendapatkan ukuran panjang dan lebar dari gambar yang telah diupload. Sistem kemudian akan menghitung ukuran rasio dari gambar tersebut. Terdapat beberapa ukuran rasio biasanya pada gambar, yaitu 16:9, 4:3, 5:3, 8:5, dan 10:8. Bila gambar yang di upload tidak memiliki spesifikasi rasio yang telah disebutkan sebelumnya, maka rasio akan dihitung secara manual oleh sistem. Setelah rasio dari gambar yang telah di upload sudah terhitung oleh sistem, sistem akan menampilkan ukuran panjang dan lebar dalam satuan centimeter $(\mathrm{cm})$ dan user harus memilih salah satu dari ukuran yang telah ditentukan oleh sistem. Ukuran tersebut nantinya yang digunakan untuk menghitung panjang dan lebar frame serta dapat menghitung berat dan harga dari material yang digunakan. Setelah user memilih ukuran tersebut, sistem akan membawa user berpindah ke halaman kustomisasi frame.

\section{Kustomisasi Frame}

Pada tahap ini merupakan tahapan dimana user dapat melakukan kustomisasi. User dapat memilih bahan yang ingin digunakan. Bahan tersebut adalah linen, kaca, cover, dan pinggiran frame. Bahan-bahan yang dipilih nantinya akan secara otomatis tampil sesuai pada sebelah kiri layer sesuai dengan yang dipilih oleh user.
Misalnya user memilih menggunakan kaca maka foto yang tampak akan sedikit buram. Begitu juga bila user memilih bahan kaca doff. Seperti pada gambar 3, foto akan terlihat lebih buram. User dapat memilih material yang telah tersedia sesuai dengan yang diinginkan. Harga dan berat akan secara otomatis berubah sesuai dengan yang dihitung oleh sistem dan secara otomatis akan tampil. User juga dapat melakukan download gambar dari hasil yang persis pada tampilan sebelah kiri layar. User juga dapat melihat sisi samping frame dengan menekan tombol side view.
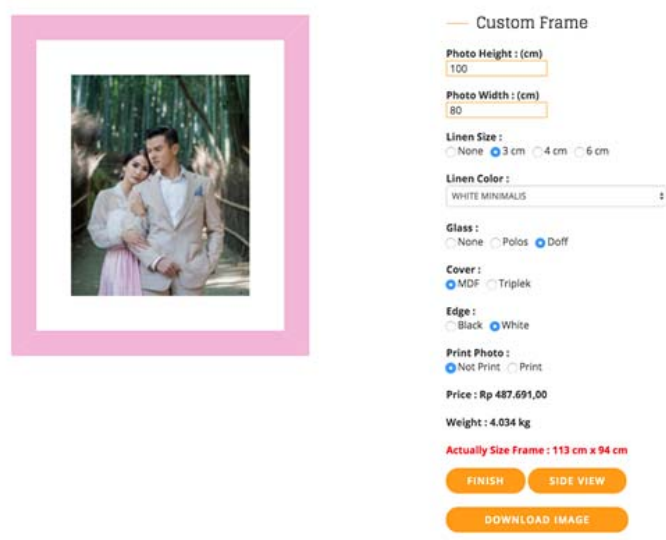

Gambar. 3. Kostumisasi Frame

\section{Perhitungan Berat dan Harga}

Berat yang dihitung saat user melakukan kustomisasi adalah berat dari frame, berat dari linen bila user memilih ukuran linen, berat kaca, dan berat penutup. Begitu juga dengan harga. Harga akan secara otomatis terhitung saat user melakukan kustomisasi pada saat user memilih linen, kaca, penutup, dan ingin mencetak foto atau tidak. Harga tersebut akan secara otomatis dihitung oleh sistem dan akan tampil pada website.

Price $=\frac{\mathrm{X}}{100} * \frac{\mathrm{Y}}{100} *$ material price

Rumus 1 merupakan rumus yang digunakan untuk menghitung harga material pada saat user melakukan kustomisasi frame. Harga yang dihitung saat user melakukan kustomisasi adalah harga dari frame, harga dari linen, harga dari kaca, dan harga dari penutup frame. Misalnya seorang user melakukan kustomisasi frame dengan ukuran 30 x 40 centimeter. Harga frame 1 x 1 meter adalah 320 ribu rupiah. Maka untuk mendapatkan harga frame untuk ukuran 30 × 40 centimeter adalah ( $30 / 100$ ) x ( $40 /$ $100) * 320000$. Maka harga frame untuk ukuran $30 \times 40$ centimeter adalah 38.400 rupiah. Harga ini belum termasuk linen, kaca, dan penutup frame. Untuk mendapatkan harga total tersebut adalah sistem akan mencari secara otomatis harga dari tiap material yang digunakan seperti pada contoh diatas. Setelah itu harga tiap material akan dijumlahkan sehingga sistem akan mendapatkan harga total dari kustomisasi frame tersebut.

Weight $=\frac{\mathrm{X}}{100} * \frac{\mathrm{Y}}{100} *$ material weight 
Rumus 2 merupakan rumus yang digunakan untuk menghitung berat material pada saat user melakukan kustomisasi frame. Berat yang dihitung saat user melakukan kustomisasi adalah berat dari frame, berat dari linen, berat dari kaca, dan berat dari penutup frame. Misalnya seorang user melakukan kustomisasi frame dengan ukuran 30 x 40 centimeter. Berat frame 1 x 1 meter adalah 1 kilogram. Maka untuk mendapatkan berat frame untuk ukuran 30 x 40 centimeter adalah adalah ( $30 / 100) \times(40 / 100) * 1$. Maka berat frame untuk ukuran $30 \times 40$ centimeter adalah 0,12 kilogram atau 120 gram. Berat ini belum termasuk linen, kaca, dan penutup frame. Untuk mendapatkan berat total tersebut adalah sistem akan mencari secara otomatis berat dari tiap material yang digunakan seperti pada contoh diatas. Setelah itu berat tiap material akan dijumlahkan sehingga sistem akan mendapatkan berat total dari kustomisasi frame tersebut.

\section{E. Penggunaan Konva JS pada Kustomisasi Frame}

Penggunaan library javascript pada konva js digunakan untuk menyusun kerangka pigura pada kanvas. Penyusunan kerangka canvas pigura ini dibagi menjadi 4 bagian. Bagian tersebut adalah kerangka foto, kerangka pinggiran, kerangka linen, dan kerangka frame. Semua kerangka canvas tersebut dapat diatur background gambar dan ukuran gambarnya. Tiap kerangka canvas terbagi menjadi 8 bagian atau 8 class, kecuali untuk kerangka canvas pada foto. Kerangka tersebut adalah 4 sisi canvas pinggiran atau canvas linen atau canvas frame dan 4 sudut canvas pada pinggiran atau canvas linen atau canvas frame. Susunan canvas yang dibuat adalah sudut-sisi-sudut-sisi hingga membentuk persegi. Tiap sisi ataupun sudut tersebut dapat diatur model gambar dan ukuran yang diinginkan. Untuk pemanggilan gambar dan ukuran pada canvas pun cukup mudah karena Konva JS sudah menyediakan function yang dapat digunakan dengan mudah untuk mengaturnya. Penggunaannya pun cukup memanggil class yang diinginkan lalu di atur width dan height serta background source nya. Background pun dapat diatur seberapa blur gambar yang diinginkan. Pada website yang dikembangkan, blur digunakan untuk penggunaan bahan kaca yang dipilih oleh user. Terdapat 2 jenis kaca yang dapat dipilih oleh user, yaitu kaca polos dan kaca doff. Menampilkan gambar sedikit blur pada gambar secara real agar user mengetahui bila user memilih untuk menggunakan kaca doff maka gambar yang akan ditempel pada pigura akan terlihat lebih blur dari pada menggunakan kaca polos.

\section{UлI COBA}

Berikut ini akan dijelaskan hasil uji coba mengenai website kustomisasi frame yang dikembangkan.

Hasil uji coba juga dilakukan pada bagian admin dimana pada bagian admin berfungsi untuk menginputkan data master frame. Pada saat uji coba dilakukan, semua inputan serta proses yang dilakukan berjalan dengan baik. Begitu juga pada website pada kustomisasi frame. Dapat dilihat pada gambar 6 fitur kustomisasi berjalan dengan baik dan 94,4 \% mengatakan bahwa fitur kustomisasi tidak sulit.

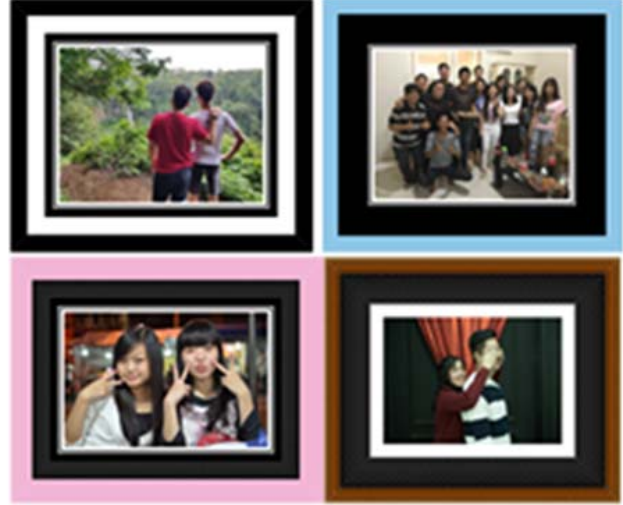

Gambar. 4. Hasil Kustomisasi Frame Material Linen

Uji coba ini menggunakan material kaca polos dan menggunakan pinggiran berwarna hitam pada gambar bagian atas. Sedangkan gambar pada bagian bawah menggunakan pinggiran berwarna putih.

Gambar 4 merupakan hasil kustomisasi frame dengan melakukan kustomisasi material pada bagian linen. Pada gambar kiri atas frame tersebut menggunakan linen berwarna putih dengan tebal $3 \mathrm{~cm}$. Pada gambar kanan atas frame tersebut menggunakan linen berwarna hitam dengan tebal $4 \mathrm{~cm}$. Pada gambar bagian bawah, frame menggunakan linen berwarna hitam motif tetapi pada gambar sebelah kiri menggunakan linen dengan tebal $3 \mathrm{~cm}$ sedangkan pada bagian kanan menggunakan linen dengan tebal $4 \mathrm{~cm}$.

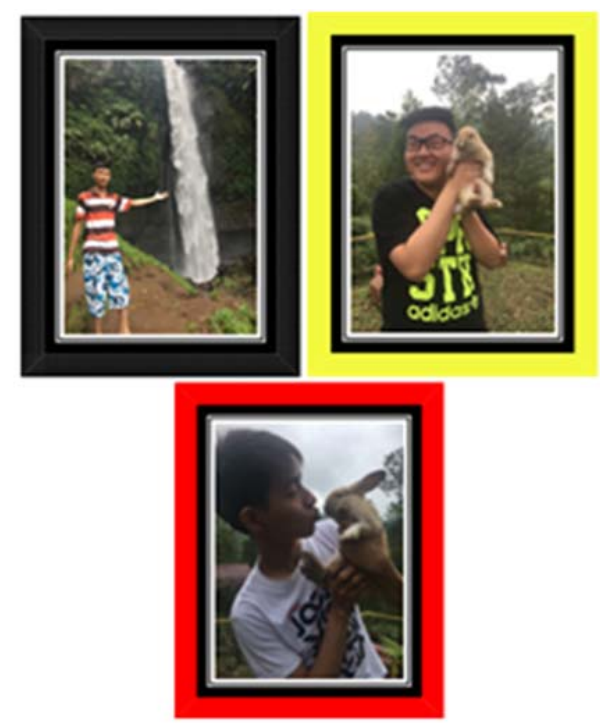

Gambar. 5. Hasil Kustomisasi Frame Material Kaca

Gambar 5 merupakan hasil kustomisasi frame dengan melakukan kustomisasi material pada bagian kaca. Pada gambar bagian kiri atas, frame tersebut tidak menggunakan kaca, sedangkan gambar kanan atas dan gambar bawah menggunakan material kaca. Gambar pada bagian kanan atas menggunakan kaca polos sehingga gambar tampak blur sebesar $10 \%$ sedangkan pada gambar bagian bawah menggunakan kaca doff dengan blur sebesar $25 \%$. 
Speed dalam membuka web

54 responses

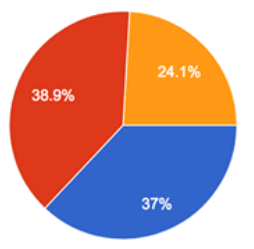

Cepat

Biasa Saja
Lambat

Bagaimana dengan navigasi dan fitur yang ditawarkan? Apakah sudah mencukupi dan memudahkan?

54 responses
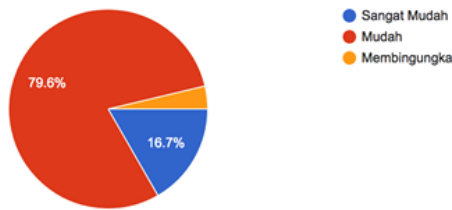

Bagaimana gambar yang terdapat dalam website tersebut? 54 responses
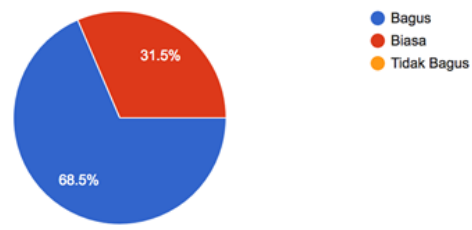

Bagaimana fitur customization frame yang terdapat pada website? 54 responsees

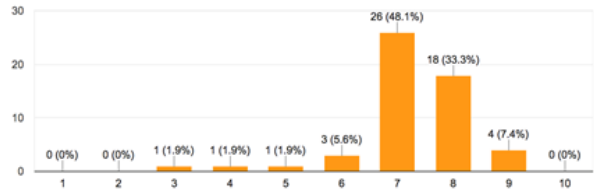

Apakah fitur customization frame terlalu rumit? 54 responses

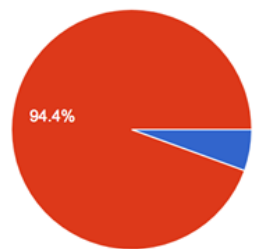$$
\text { Ya }
$$

Gambar. 6. Hasil Kuisioner

\section{KESIMPULAN}

Selama proses uji coba, dapat ditarik beberapa kesimpulan sebagai berikut:

1) $68,5 \%$ pengguna berpendapat bahwa gambar yang ada pada website cukup bagus, tetapi $24,1 \%$ pengguna website berpendapat bahwa speed dalam membuka website lambat. Itu dikarenakan gambar yang terdapat pada website cukup besar sehingga akses website perlu didukung speed internet yang cukup cepat agar website kustomisasi frame ini dapat berjalan dengan lancar.

2) Fitur kustomisasi berjalan dengan baik. Dari ujicoba yang dilakukan, 94,4\% berpendapat bahwa fitur kustomisasi frame dapat memudahkan pengguna untuk melakukan kustomisasi gambar, sehingga dapat dikatakan bahwa website yang dikembangkan sangat user friendly.

3) Penggunaan library KonvaJS sangatlah membantu dalam membuat kerangka pigura. Dengan menggunakan library ini, tidak perlu lagi membuat model kerangka pigura dari awal dengan mengatur model menggunakan html, css, dan javascriptnya karena KonvaJS sudah membantu dan melengkapi ketiga hal tersebut sehingga ukuran pada model pigura yang diinginkan dapat dengan mudah dirangkai untuk ditampilkan dari yang berupa potongan gambar frame yang tersimpan menjadi tersusun berbentuk pigura.

\section{DAFTAR PUSTAKA}

[1] Marcello Migliore. Integrating a Digital Picture Frame. Congress of the European Society of Thoraric Surgery, 2010. Pp:63-64.

[2] Rahmadiansyah, D. \& Irawan, D., "Implementasi Metode Model View Controller Menggunakan Framework CodeIgniter dalam Pengembangan Aplikasi Manajemen Depo Petikemas pada Unit Usaha Belawan Logistics Center", Seminar Nasional Teknologi Informasi dan Komunikssi (SNASTIKON), pp. 1-6. 2012.

[3] Riyanto, Membuat Sendiri Aplikasi E-Commerce dengan PHP dan MySQL Menggunakan Codeigniter dan Jquery, Yogyakarta, ANDI, 2011

[4] Zakir, A., "Rancang Bangun Responsive Web Layout dengan Menggunakan Bootstrap Framework", Jurnal Nasional Informatika dan Teknologi Jaringan, p. 7. 2016.

[5] Supono \& Putratama, V., Pemrograman Web dengan Menggunakan PHP dan Framework Codeigniter, Yogyakarta, Deepublish, 2016. 